\title{
The recover from the excision in head and neck of femoral after therapy with low level laser
}

\author{
Cristina Pacheco-Soares ${ }^{1}$, Carmen de Lurdes Moreira Gusmão ${ }^{1}$, Patricia D. M. Ferreira ${ }^{1}$, \\ Miguel A. C. Salgado ${ }^{2}$ \\ ${ }^{1}$ Dynamics of Cellular Compartments Laboratory, Research and Development Institute, Universidade do Vale do Paraíba, São Paulo, \\ Brazil \\ ${ }^{2}$ Histology Laboratory, Faculty of Odontology, Universidade Estadual de São Paulo, São Paulo, Brazil \\ Email: cpsoares@univap.br
}

Received 1 June 2011; revised 21 August 2011; accepted 21 November 2011

\begin{abstract}
Degenerative articulate diseases, resulting from dysplasia and aseptic necrosis of the femoral head and neck, chronic dislocation of the femur and osteoarthrosis, are often treated surgically by an excision in the femoral head and neck. This procedure entails the formation of a false fibrous articulation, providing pain relief. The action of low level laser therapy (LLLT) has been described in orthopedic applications, to repair both bone and articular tissue. LLLT has demonstrated favorable results in vitro and in vivo in stimulating bone repair. A diode laser, $650 \mathrm{~nm}$, with a potency of $30 \mathrm{~mW}$, was used trans-surgically to irradiate. A diode laser $(780 \mathrm{~nm}$ and the potency of $\mathbf{4 0}$ $\mathrm{mW}$ ) was used on the skin for post-surgery applications. For the experiment, 10 clinically normal New Zealander rabbits underwent surgery and were then divided into two groups, one submitted to irradiation and the other kept for sham. Fifteen days after the surgery, samples of the newly formed tissue were collected from both groups, for macroscopic evaluation of the fibrous pseudo-articulation forming process on the irradiated and sham groups. The macroscopic and microscopic appearance of the samples, suggest that the utilization of the LLLT in the formation of fibrous pseudo-articulation was effective in accelerating the cicatrization process and in improving the quality of the formed tissue.
\end{abstract}

Keywords: Diode Laser; Femoral Leson; Excision

\section{INTRODUCTION}

Hip fractures are one of most common musculoskeletal problems in the elderly and also may occur in younger people. Considering its frequency and that life expediency in increasing worldwide, research on hip fracture is of paramount importance. This fracture may occur due to decreased bone mineral, i.e., osteoporosis, constant friction in the hip joint, or arthritis, as well as because of traumatic accidents that cause bone fracture.

Articular pathologies, such as degenerative articulate diseases resulting from dysplasia, aseptic necrosis of the femoral head and neck, chronic femoral luxation and osteoarthrosis, are frequently treated surgically, by making an excision in femoral head and neck. This surgery permits the formation of a false fibrous articulation, which promotes pain relief by eliminating the contact between the femur and the pelvis bones, by creating scar tissue [1].

Low level laser therapy (LLLT) is gaining popularity in a variety of clinical applications. It may enhance revascularization, promote angiogenesis, and increase collagen synthesis to promote healing of acute [2] and chronic wounds [3]. LLLT accelerated healing of cutaneous wound in rats with a biphasic dose response favoring lower doses [4]. LLLT can also stimulate healing of deeper structures such as nerves [5], tendons [6], cartilage [7], bones [8] and even internal organs [9]. It can reduce pain [10], inflammation [11], and swelling [12] caused by injuries, degenerative diseases, or autoimmune diseases. Morrone et al. 2000 [7] investigated the effects of gallium-aluminum-arsenide (Ga-Al-As) laser on osteochondral defects of rabbits. Results after LLLT showed faster healing of the defect, an overall improvement in cellular morphology, and a more regular appearance of the osteochondral tissue [7,13]. Guzzardella et al. 2001 [13], studying surgical osteochondral defects subjected intraoperatively to the diode Ga-Al-As laser $(780 \mathrm{~nm}$, $300 \mathrm{~J} / \mathrm{cm}^{2}, 1 \mathrm{~W}, 300 \mathrm{~Hz}, 10 \mathrm{~min}$ ), showed good results in cell morphology and a regular appearance of the repaired osteochondral tissue. On the other hand, Otsuka et al., 1997 [14] reported that, in a rabbit model, small cylindrical full-thickness defects ( $\leq 3 \mathrm{~mm}$ in diameter) spon- 
taneously regenerated the epiphysial structure, including the articular cartilage and the subchondral bone up to the original bone-articular junction.

Calatrava, et al. 1997 [15] developed a study to assess effects of LLLT irradiation on experimental lesions of articular cartilage using laser infrared (IR) and Helium Neon (He-Ne). Their results statistically demonstrated an increase in anti-inflammatory capacity of infrared laser.

Functional recovery was similar in both treatments. The histological study showed hyaline cartilage in the IV group, fibroblast in the He-Ne group, and granulation tissue in the control group. Clinical results and histological indicated that the treatment with laser clearly had an anti-inflammatory effect, which promoted a speedy recovery and articulate regeneration.

Pires-Oliveira et al. 2010 [16] demonstrated the action of As-GA laser irradiation $\left(904 \mathrm{~nm}, 50 \mathrm{~mJ} / \mathrm{cm}^{2}\right)$ on bone repair in tibia of osteopenic rats using bone densitometry and histomorphometric analyses. The authors found this irradiation model accelerated the repair process in osteopenic fractures, especially in the initial phase of bone regeneration.

In the case of surgical excision of the femoral head and neck, this study used LLLT and histological to evaluate tissue repair in the formation of a fibrous pseudojoint, by analyzing the quality of the tissue formed in animals subjected to surgical excision of the femoral head and neck, and comparing groups of animals irradiated with low-power laser to groups of non-irradiated animals.

\section{MATERIALS AND METHODS}

Ten New Zealand adult rabbits, all clinically healthy were weighed and then intramuscularly (IM) injected with sulfate atropine (at a dose of $0.0044 \mathrm{mg} / \mathrm{kg}$ ). After $15 \mathrm{~min}$ utes they were anesthetized by $0.25 \mathrm{ml} / \mathrm{kg}$ of $2 \% \mathrm{xy}-$ lazine, $0.3 \mathrm{ml}$ of tiletamine/zolazepam (Zoletyl Tele$\mathrm{zol}^{\circledR}$ or Virbaxyl Rompum ${ }^{\circledR}$ ) IM. Trichotomy was made in the region to be focused on and the skin disinfection with Povidone ${ }^{\circledR}$. Next, an incision was made in the skin in the crescent-shaped dorsal region of the greater trochanter and the gluteal muscles located dorsally were removed. The femoral neck was cut, with the limb in external rotation. Once the femoral head and neck were free, these structures were excited by a bone forceps to allow the cutting of soft tissue adhesions and the remaining section round ligament, which retreated toward the acetabulum.

The first irradiation was immediately performed on 6 animals; with the other four remained as sham. Using laser diode $650 \mathrm{~nm}, 30 \mathrm{~mW}$ at a dose of $4.5 \mathrm{~J} / \mathrm{cm}^{2}$ for each point, this step was performed on the open incision in the following areas: 1) the femoral neck, perpendicular to the femur; 2) region of the acetabulum, where the sec- tioned round ligament is located; and 3) two regions of the joint capsule. The layers of tissue were then sutured and penicillin Benzatila (Agropen $\mathrm{LA}^{\circledR} 50 \mathrm{mg} / \mathrm{kg}$ ) injected. The region of the greater trochanter was located by palpation, which was circled by a felt tip pen to identify the area to irradiate in the next step.

After 24 hours, the marked area and the areas initially treated were again irradiated, through the skin, with 780 $\mathrm{nm}$ laser diode, $40 \mathrm{~mW}$ at a dose of $4 \mathrm{~J} / \mathrm{cm}^{2}$ for each point. The animals in the sham group were submitted to these procedures, but with the laser disconnected. Eight sessions were performed, the first five with intervals of 24 hours and the subsequent with intervals of 48 hours. Table 1 presents the protocol of irradiation.

Fifteen and thirty days after surgery, the animals were sacrificed, using $2 \%$ xylazine at a dose of $5 \mathrm{mg} / \mathrm{kg}, 15$ $\mathrm{mg} / \mathrm{kg}$ IM Zoletyl ${ }^{\circledR}$. After general anesthesia, each animal received an ampoule of potassium chloride $\left(\mathrm{KMnO}_{4}\right)$ by intracardiac route. The hip joint region of each operated limb was removed for macroscopic and microscopic studies of tissue repair to compare the irradiated group with the sham. The specimens were processed according to routine histological technique in the Laboratory of Histology FOSJC-UNESP.

\section{RESULTS}

The macroscopic analysis of the joint showed accentuated fibrous tissue within the joint cavity and the presence of trabecular bone in the medullary region of the femur in the irradiated group compared with the sham group, 15 days after surgery (Figure 1).

The microscopic analysis of the sham group revealed the presence of femoral trabecular bone covered by osteoblasts and many osteoclasts, while the irradiated groups had femoral trabecular bone formed by numerous thin, anastomosing delimited cavities with spinal cord tissue having a fibrous and much vascularized appearance. The acetabulum had dense bone tissue containing bone trabeculae lined by osteoblasts and osteocytes in the matrix.

Table 1. Irradiation protocol.

\begin{tabular}{cccc}
\hline \multicolumn{2}{c}{1 stage } & \multicolumn{2}{c}{2 stage } \\
\hline $\begin{array}{c}\text { Energy Density } \\
\text { (by point) }\end{array}$ & $4.5 \mathrm{~J} / \mathrm{cm}^{2}$ & $\begin{array}{c}\text { Energy Density } \\
\text { (by point) }\end{array}$ & $4.0 \mathrm{~J} / \mathrm{cm}^{2}$ \\
Power & $30 \mathrm{mw}$ & Power & $40 \mathrm{mw}$ \\
$\lambda$ & $650 \mathrm{~nm}$ & $\lambda$ & $780 \mathrm{~nm}$ \\
Beam Area & $1 \mathrm{~cm}^{2}$ & Beam Area & $1 \mathrm{~cm}^{2}$ \\
$\begin{array}{c}\text { Irradiation time } \\
\text { (by point) }\end{array}$ & $3 \mathrm{~s}$ & $\begin{array}{c}\text { Irradiation time } \\
\text { (by point) }\end{array}$ & $2 \mathrm{~s}$ \\
\hline
\end{tabular}



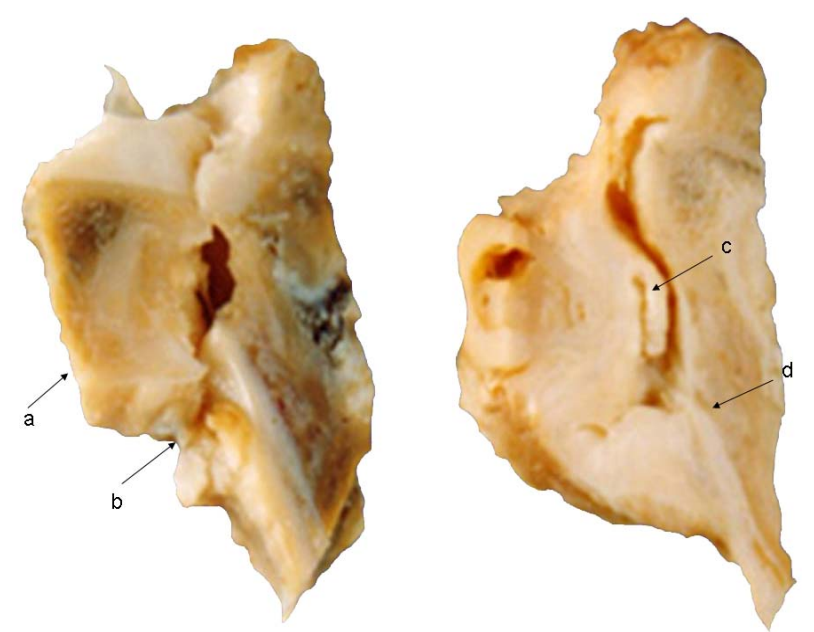

Figure 1. Group Sham: (a) Little obvious presence of fibrous tissue, limited to the articular surface of acetabulum; (b) Medullary portion of femur showing bone trabeculae with irregular arrangement; Group irradiated; (c) Markedly formation of fibrous tissue filling the joint cavity; (d) Region medullary trabecular bone Femur showing regularly arranged.

Areas of hyaline cartilage were present in the trochanter region, indicating the formation of bone trabeculae (Figures 2(A)-(D)).

The analysis of the sham group after 30 days showed the presence of fibrous cartilage tissue, slightly vascularized, with numerous chondroid appearing cells (arrow) protruding between articular surfaces. Compared to the irradiated group they had coated acetabular trabeculae with few flattened shape osteoblasts and a dense layer of loosely connected rich cellular and vascular tissue interposed between the surfaces. The region of the acetabulum with joint space showed a densely fibrous and a richly cellular and vascular layer with a coating similar to the synovium (Figures 3(A)-(D)).

\section{DISCUSSION}

The effects of low level laser therapy (LLLT) in different tissues may be considered therapeutically beneficial. The laser light stimulates tissue regeneration, which increases the production of collagen and has an anti-inflammatory effect, resulting from its action on the microcirculation, and is also analgesic. The effect of LLLT on bone regeneration may depend not only on the total dose of irradiation but also on the irradiation time and mode. Some previous reports recognize positive effects of LLLT on bone [17]. This may possibly be corroborated by several previous studies in which LLLT was used in odontology treatments [18-21].

However, some reports $[14,22]$ have suggested that LLLT could improve bone matrix production due to improved vascularization and anti-inflammatory effects. These would result in an increase in both the release of

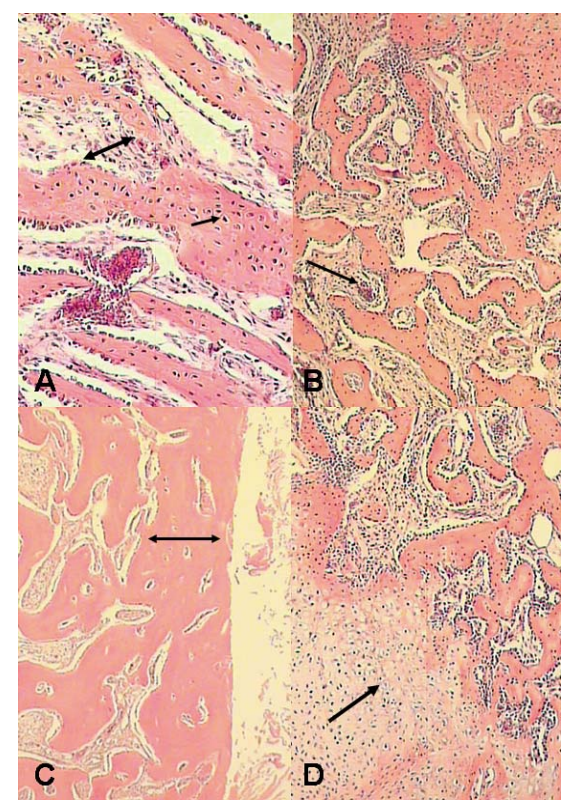

Figure 2. Photomicrograph of the group 15 days: (A) Sham group, there is the femur bone trabeculae lined by osteoblasts (double arrow) and a large number of osteoclasts (arrow); (B) Irradiated group, there is femoral bone, numerous trabeculae thin, anastomosing, medullary tissue containing fibrous aspect and very vascularized (arrow); (C) Irradiated group. The double arrow indicates the dense bone of the acetabulum, the arrow indicates the trabecular bone lined with osteoblasts, osteocytes arrowhead indicates the matrix; (D) Irradiated group. The arrow indicates an area of hyaline cartilage in the region distal to the trochanter related to the formation of trabecular bone surface. $\mathrm{H} \& \mathrm{E}$.

mediators and microvascularization, which would accelerate bone healing.

Guzzardella et al., (2001) [13], described that the condyles of rabbits injured and treated with laser diode Aluminum Gallium Arsenide (780 nm) showed good cell morphology and organization of osteocartilaginous tissue repair. This corroborates the results obtained in our study, in which the histological analysis of irradiated animals 15 days after surgery showed the formation of numerous thin trabeculae, anastomosing, delimited medullary cavity, and medullary tissue, which was fibrous in appearance and much vascularized. The trabeculae were lined by a layer of osteoblasts, a large number of osteoclasts in small gaps, showing intense activity and bone formation of bone matrix after irradiation.

When the sham group was assessed, there was a dense layer of fibrous tissue neoformation, with small areas of necrotic tissue on its surface. The peripheral bone tissue showed a denser arrangement and new trabeculae delim- 


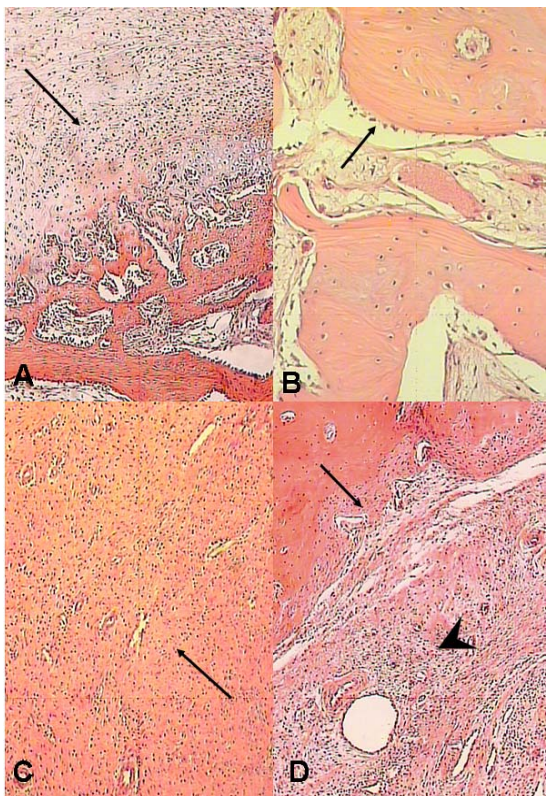

Figure 3. Photomicrograph of the group 30 days (A) Observed the presence of fibrous cartilage tissue, little vascularized, with numerous cells of chondroid appearance (arrow) protruding between articular surfaces; (B) Irradiated group, with the acetabular trabeculae lined by osteoblasts few flattened shape (arrow); (C) Irradiated group, shows abundant layer of loose connective tissue richly vascular and cellular (arrow) interposed between the surfaces; (D) Irradiated group, we observe the surface of the acetabulum toward the joint space showing dense fibrous layer richly cellular and vascular (arrowhead) with a layer of synovial-like coating (arrow). H \& E.

iting large marrow cavities, the fibrous marrow tissue was presented, with some pockets of fat cells and normal appearing tissue in more remote areas from the healing region (Figure 2(A)).

In the irradiated group (30 days post surgery), the femoral bone showed healing in the region, with the articular surface with trabeculae of variable thickness, lined by osteoclasts, forming unevenly distributed layers, delimiting the fibrous medullary tissue and very vascular. In the region near the trochanter and distal to it, there was a large area of hyaline cartilage, related to the process of bone formation, and the fibrocartilaginous articular surface had areas of chondroid tissue (Figure 3(B)). Similar results were obtained by Torricelli et al., 2001 [22] with biostimulation in chondrocytes cultures. In relation to the acetabulum, a few trabeculae were observed, ranging from thin to thick, covered with a few osteoblasts. The medullary tissue had a fibrous and less cellular appearance, though in more remote regions of lesions it appeared normal. The surface facing the joint space had a dense fibrous layer, which was richly cellular and vascular with a coating layer similar to the synovial (Figure 3(C)).

The femoral tissue of the sham group (30 days), showed a process of bone remodeling and fibrous connective tissue repair, with cell-rich chondroid covering its surface. This tissue had a covering of cells that resembled the synovial membrane. The trabecular bone surface contained a thin, irregular anastomosing, covered by a few osteoblasts with numerous irregularly distributed osteoclasts (Figure 3(A)). There had also the presence of fibrous cartilage tissue, slightly vascularized, with numerous chondroid appearing cells, lined by synovia, with projections from the articular surface (Figure 3(D)).

The results described here suggest the use of LLLT as an aid in the formation of a fibrous pseudo-joint to accelerate the healing process and improve the quality of formed tissue, thus enabling the animals subjected to this type of procedure a better and more rapid recovery, thereby suggesting the application of LLLT in physical therapy in patients with femoral neck fracture or excision of the femoral head.

The protocol of this study is consistent with the Ethical Principles in Animal Experimentation (COBEA/June 1991) and follows the Standards for the Practice of Scientific-Didactic Vivisection of Animals (Law 6638 of 08.05.1979) and was therefore approved by the Research Ethics Committee of UNIVAP.

\section{ACKNOWLEDGEMENTS}

We thank Fundação Valeparaibana de Ensino, Brazil for supporting this work.

\section{REFERENCES}

[1] Brinker, W.O., Piermattei, D.L. and Flo, G.L. (1986) Manual de Ortopedia e tratamento das fraturas dos pequenos animais. Manole, São Paulo.

[2] Hopkins, J.T., McLoda, T.A., Seegmiller, J.G. and Baxter, G.D. (2004) Low-level laser therapy facilitates superficial wound healing in humans: A triple-blind, sham-controlled study. Journal of Athletic Training, 39, 223- 229.

[3] Yu, W., Naim, J.O. and Lanzafame, R.J. (1997) Effects of photostimulation on wound healing in diabetic mice. $\mathrm{La}$ sers in Surgery and Medicine, 20, 56-63.

doi:10.1002/(SICI)1096-9101(1997)20:1<56::AID-LSM9 $>3.0 . \mathrm{CO} ; 2-\mathrm{Y}$

[4] Corazza, A.V., Jorge, J., Kurachi, C. and Bagnato, V.S. (2007) Photobiomodulation on the angiogenesis of skin wounds in rats using different light sources. Photomedicine and Laser Surgery, 25, 102-106. doi:10.1089/pho.2006.2011

[5] Gigo-Benato, D., Geuna, S., De Castro Rodrigues, A., Tos, P., Fornaro, M., Boux, E., Battiston, B. and Giacobini-Robecchi, M.G. (2004) Low-power laser biostimula- 
tion enhances nerve repair after end-to-side neurorrhaphy: A double-blind randomized study in the rat median nerve model. Lasers in Medical Science, 19, 57-65. doi:10.1007/s10103-004-0300-3

[6] Fillipin, L.I., Mauriz, J.L., Vedovelli, K., Moreira, A.J., Zettler, C.G., Lech, O., Marroni, N.P. and Gonzalez-Gallego, J. (2005) Low-level laser therapy (LLLT) prevents oxidative stress and reduces fibrosis in rat traumatized Achilles tendon. Lasers in Surgery and Medicine, 37, 293-300. doi:10.1002/lsm.20225

[7] Morrone, G., Guzzardella, G.A., Torricelli, P., Rocca, M., Tigani, D., Brodano, G.B., Fini, M. and Giardino, R. (2000) Osteochondral lesion repair of the knee in the rabbit after low-power diode Ga-Al-As laser biostimulation: An experimental study. Artificial Cells Blood Substitute Immobilization Biotechnology, 28, 321-336.

[8] Weber, J.B., Pinheiro, A.L., de Oliveira, M.G., Oliveira, F.A. and Ramalho, L.M. (2006) Laser therapy improves healing of bone defects submitted to autologous bone graft. Photomedicine Laser Surgery, 24, 38-44. doi:10.1089/pho.2006.24.38

[9] Shao, X.H., Yang, Y.P., Dai, J., Wu, J.F. and Bo, A.H. (2005) Effects of He-Ne laser irradiation on chronic atrophic gastritis in rats. World Journal of Gastroenterology, 11, 3958-3961.

[10] Bjordal, J.M., Johnson, M.I., Iversen, V., Aimbire, F. and Lopes-Martins, R.A. (2006) Photoradiation in acute pain: A systematic review of possible mechanisms of action and clinical effects in randomized placebo-controlled trials. Photomedicine Laser Surgery, 24, 158-168. doi:10.1089/pho.2006.24.158

[11] Bjordal, J.M., Lopes-Martins, R.A. and Iversen, V.V. (2006) A randomised, placebo controlled trial of low level laser therapy for activated Achilles tendinitis with microdialysis measurement of peri-tendinous prostaglandin E2 concentrations. British Journal of Sports Medicine, 40, 76-80. doi:10.1136/bjsm.2005.020842

[12] Carati, C.J., Anderson, S.N., Gannon, B.J. and Piller, N.B. (2003) Treatment of postmastectomy lymphedema with low-level laser therapy: A double blind, placebo-controlled trial. Cancer, 98, 1114-1122. doi:10.1002/cncr.11641

[13] Guzzardella, G.A., Tigani, D., Torricelli, P., Fini, M., Martini, L., Morrone, G. and Giardino, R. (2001) Lowpower diode laser stimulation os surgical osteochondral defects: Results after 24 weeks. Artificial Cells, Blood Substitutes and Imobilization Biotechnology, 29, 235-244. doi:10.1081/BIO-100103047
[14] Ostuka, Y., Mizuta, H., Takagi, K., Lyama, K.I., Yoshitake, Y., Nishikawa, K., Suzuki, F. and Hiraki, Y. (1997) Requirement of fibroblast growth factor signaling for regeneration of epiphysial morphology in rabbit full thickness defects of AC. Development-Growth Differentiation, 39, 143-156. doi:10.1046/j.1440-169X.1997.t01-1-00003.x

[15] Calatrava, I.R., Valenzuela, J.M.S., Vilamandos, R.J., Redondo, J.I., Vilamandos, J.C. and Jurado, I.A. (1997) Histological and clinical responses of articular cartilage to LLLT: Experimental study. Lasers in Medical Science, 12, 117-121. doi:10.1007/BF02763980

[16] Pires-Oliveira, D.A.A., Oliveira, R.F., Amadei, S.U., Pacheco-Soares, C. and Rocha, R.F. (2010) Laser $904 \mathrm{~nm}$ action on bone repair in rats with osteoporosis. Osteoporosis International, 21, 2109-2114. doi:10.1007/s00198-010-1183-8

[17] Saito, S. and Shimizu, N. (1997) Stimulatory effects of low-power laser irradiation on bone regeneration in midpalatal suture during expansion in the rat. American Journal of Orthodontics and Dentofacial Orthopics, 111, 525532.

[18] Luger, E.J., Rockhind, S., Wollman, Y., Kogan, G. and Dekel, S. (1998) Effect of low-power laser irradiation on the mechanical properties of bone fracture healing in rats. Lasers in Surgery and Medicine, 22, 97-102. doi:10.1002/(SICI)1096-9101(1998)22:2<97::AID-LSM5 $>3.0 . \mathrm{CO} ; 2-\mathrm{R}$

[19] Yaakobi, T., Maltz, L. and Oron, U. (1996) Promotion of bone repair in the cortical of the tibia in rats by low energy laser (He-Ne) irradiation. Calcified Tissue International, 59, 297-300. doi:10.1007/s002239900126

[20] Freitas, A.C., Pinheiro, A.L.B., Miranda, P., Thiers, F.A. and Vieira, A.L.B. (2001) Assessment of anti-inflammatory effect of $830 \mathrm{~nm}$ laser light using c-reactive protein levels. British Dental Journal, 12, 187-190.

[21] Takeda, Y. (1988) Irradiation effect of low-energy laser on alveolar bone after tooth extraction: Experimental study in rats. International Journal of Oral and Maxillofacial Surgery, 7, 388-391. doi:10.1016/S0901-5027(88)80070-5

[22] Torricelli, P., Giavaresi, G., Fini, M., Guzzardella, G.A., Morrone, G. and Girdino, R. (2001) Laser bioestimulation of cartilage, in vitro evaluation. Biomedicine and Pharmacotherapy, 55, 117-120. doi:10.1016/S0753-3322(00)00025-1 